\title{
En busca del sol: viajes, islas paraísos, discursos sanitarios y distopías del trópico en el siglo XIX
}

\author{
In search of the sun: travel, paradise islands, speeches \\ sanitary and dystopias of the tropics in the nineteenth century \\ Em busca do sol: viagens, ilhas paradisíaca, discursos \\ higiénicos e distopias dos trópicos no século XIX
}

Leguis Antonio Gómez Castaño ${ }^{1}$ iD

Tenerife, Islas Canarias

Para citaciones: Gómez, L. (2021). En busca del sol: viajes, islas paraísos, discursos sanitarios y distopías del trópico en el siglo XIX. El Taller de la Historia, 13(1), 125-150.

Recibido: diciembre 2020

Aprobado: febrero de2021

Editor: Sergio Paolo Solano. Universidad de Cartagena-Colombia.
Copyright: () 2021. Gómez, L. Este es un artículo de acceso abierto, distribuido bajo los términos de la licencia https://creativecommons.org/licenses/by-ncsa/4.0/ la cual permite el uso sin restricciones, distribución y reproducción en cualquier medio, siempre y cuando que el original, el autor y la fuente sean acreditados.

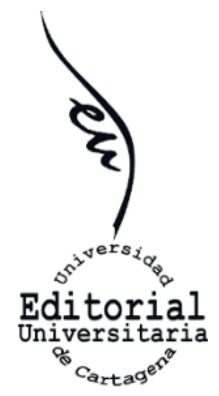

\section{RESUMEN}

La necesidad de mejores fluctuaciones climáticas para pacientes afectados por condiciones respiratorias, generó en la Europa del siglo XIX una búsqueda de geografías de la salud que se evidenció con la creación de sitios de veraneo localizados en los países del sur del continente, pero que posteriormente los llevaría a moverse hacia el trópico, especialmente en unas islas localizadas en el punto medio entre el frio del norte y el calor del sur. Hubo también la intención de extender esos sitios saludables a algunas islas de Caribe, así como algunas ciudades de los Andes como Bogotá y Lima, pero sin los resultados esperados. Al final, el trópico se convertiría no solo en el espacio para la búsqueda de la salud, sino la geografía de las disputas imperiales.

Palabras clave: Trópico; enfermedades; discursos sanitarios; Islas Caribeñas; distopías.

\begin{abstract}
Due to medical illnesses related to respiratory diseases, there was in Europe a need for places with better climatological conditions for invalids. This situation generated initially the search for better climates during the cold seasons, which identifies some spots in southern Europe countries, but lately in XIX century, focuses its interest on the tropics, especially in those islands located in a middle zone between the cold of the north and the heat of the south. There was also, the intention to extend those healthy spots to the Caribbean as well as certain Andean cities like Bogota and Lima without the same results, but, at the end, the tropics would become the spaces not only of the search for health, but the geographies of imperial disputes.
\end{abstract}

Keywords: Tropics; diseases; health discourses; Caribbean Islands; dystopias.

\footnotetext{
${ }^{1}$ Doctor en Estudios Atlánticos, Tenerife, Islas Canarias. saudade1971@protonmail.com
} 


\section{RESUMO}

A necessidade de melhores flutuações climáticas para pacientes afetados por doenças respiratórias, gerou na Europa do século XIX uma busca por geografias de saúde que foi evidenciada com a criação de locais de verão localizados nos países do sul do continente, mas que mais tarde os levariam a se mudar para os trópicos, especialmente em algumas ilhas localizadas no ponto médio entre o frio do norte e o calor do sul. Houve também a intenção de estender esses locais saudáveis para algumas ilhas do Caribe, bem como algumas cidades dos Andes, como Bogotá e Lima, mas sem os resultados esperados. No final, os trópicos se tornariam não apenas o espaço para a busca da saúde, mas a geografia das disputas imperiais.

Palavras-chave: Trópicos; doenças; discursos de saúde; Ilhas do Caribe; distopias.

\section{Presentación}

Armado con las herramientas que la modernidad europea ponía a su alcance, en 1829, James Clark publicó los resultados de una investigación en torno al asunto del clima y sus efectos en la salud bajo el nombre The sanative influence of climate ${ }^{2}$, al cual le precedió otro estudio menos comprensivo bajo el título The influence of climate $^{3}$, Ambos trabajos, pero especialmente el primero, allanarían el camino científico para que, posteriormente, algunas geografías del trópico fueran reconocidas como ambientes propicios para la recuperación gradual de pacientes afectados por enfermedades respiratorias, consideradas perniciosas en la Europa de finales de los siglos XVIII y principios del XIX. El estudio, que incluyó evaluaciones sistemáticas de las temperaturas en distintas regiones del planeta (todas tropicales), recomendaba la estancia con base en ciertas características climáticas ${ }^{4}$, de tal forma que las condiciones de salud de los invalids ${ }^{5}$, pudiera mejorar considerablemente.

Esta publicación de Clark, no fue el resultado de un interés en el que únicamente el galeno estuviese interesado. Más bien, -y de ahí el título de este artículo-, había toda una preocupación en los círculos académicos

\footnotetext{
${ }^{2}$ James Clark, The sanative influence of climate: with an account of best places of resort for invalids, Philadelphia, A. Waldie Publisher, 1841.

${ }^{3}$ James Clark, The influence of climate in the prevention and cure of chronic diseases, London, Thomas and George Underwood Publishers, 1829.

${ }^{4}$ Se estimaba que la variabilidad del clima no debía ser muy alta, ya que ello afectaba las condiciones de salud de los pacientes, como, en efecto pasaba en la gran mayoría de los países del norte, donde los veranos eran muy cálidos y los inviernos, muy fríos. En el caso de las Islas Canarias, la temperatura media en 1834 fue de 19,2 Centígrados, con una variabilidad de solo 11 grados durante todo el año. Además de eso, el clima es predominantemente seco, debido a los vientos casi constantes y la estación lluviosa es corta. Al respecto, véase a James Clark: The influence of climate in the prevention and cure of chronic diseases. London: Thomas and George Underwood Publishers, 1829, William W. Cooper, The invalid's guide to Madeira with a description of Teneriffe, Lisboan, Cintra, Mafra, etc., London, Smith, Elder \& Co. Publishers, 1840; William R. Wilde, Narrative of a Voyage to Madeira, Tenerife and along the shores of the Mediterranean, Dublin, William Curry, Jun and Company, 1840. Two Volumes.

5 El termino Invalids se usaba en Inglaterra para denominar a aquellos pacientes que adolecían de enfermedades respiratorias. No guarda, por tanto, relación alguna con la definición al español de aquel que tiene incapacidad física, que no se vale por sus propios medios, sino que depende de los demás. Al respecto, véase el trabajo de Nicolas Gonzalez Lemus: Clima y medicina. Los orígenes del turismo en Canarias. Santa Cruz de Tenerife: Ediciones Idea, 2007. Sobre la definición de inválido, véase: http://www.wordreference.com/definicion/invalido
} 
europeos de la época, no solo por encontrar soluciones farmacológicas a las enfermedades más acuciantes, sino también, una búsqueda del sol, que se evidenciaba en el rastreo de mejores condiciones climatológicas, cada vez más cercanas al trópico. Este articulo explora algunas de las reflexiones de científicos europeos y americanos en torno al tema del clima, su efecto en la salud y la búsqueda consecuente de geografías de la salud, como he dado en llamarlas, las cuales pusieron, a la postre, de relieve que el trópico, esa región del planeta construida en la retórica de los viajeros europeos como un espacio donde la vida, en el sentido ordenado de la civilización occidental, no tenía asidero, dada su naturaleza exuberante, además de los seres degenerados que lo habitaban; era ahora, no solo el espacio de intereses médicos, sino también de intereses políticos.

Estudios sobre el tema se han abordado con bastante insistencia para el caso de las Islas Canarias, como se podrá apreciar en la bibliografía consultada; sin embargo, es poco lo que se conoce sobre búsqueda de espacios saludables en otras geografías del trópico, y de ahí el interés de este artículo en abordarlos.

En The sanative influence of climate, Clark incluía, además de la ya conocida y frecuentada lista de sitios de veraneo situados en Alemania, Bélgica, Francia, Italia, Malta y Suiza, algunas islas en el Atlántico, a saber: la isla de Madeira $^{6}$, Las Islas Canarias y las Islas Azores. Así mismo, en adición a esta lista, se sumaban ahora los nombres de algunos lugares que, por su ubicación en el Caribe, parecían contradecir las percepciones históricas tradicionales sobre estos espacios, si se quiere, más relacionados con un trópico fuerte ${ }^{7}$, es decir, calor, humedad, huracanes y una naturaleza desbordada. Hablo aquí de las islas Bermudas, Bahamas, Jamaica, Barbados y Saint Vincent, Antigua, Saint Kitts y Nevis. Al fin y al cabo, en el trópico existen zonas de menor y mayor influencia del sol, siendo las primeramente mencionadas, pertenecientes a una región más cercana a la zona templada, o zona subtropical, mientras las últimas más cercanas al ecuador, o zona tórrida.

Esto podría explicar la benevolencia de los climas entre unas y otras zonas del trópico, y tal vez la tendencia de algunos sectores médicos ingleses en querer encontrar espacios de recuperación para sus pacientes por fuera de las gélidas condiciones atmosféricas de la estación invernal europea. Sin embargo, el estudio llegaba a otras conclusiones.

\footnotetext{
${ }^{6}$ La isla de Madeira había sido considerada, durante mucho tiempo, como la poseedora del mejor clima del mundo, por tanto, fue objeto de evaluaciones climatológicas por parte de médicos de renombrada trayectoria académica y científica en Europa. Al respecto véase a: W. Cooper, The invalids guide; Charles Piazzy Smith, Madeira meteorologic, Edinburgh, David Douglas Publisher, 1882 y A. Samler Brown, Madeira and the Canary Islands. A practical and complete guide for the use of invalids and tourists, London, Sampson Low Q Marston \& Co, 1894.

${ }^{7}$ El debate sobre los efectos del clima atrajo a cientos de científicos durante finales del siglo XVIII y gran parte del siglo XIX, en este debate, el trópico fue un asunto central. Véase, por ejemplo, para el caso de Nueva Granada, los argumentos de Caldas en torno al trópico. Francisco José de Caldas, "El influxo del clima sobre los seres organizados, por Don Francisco Joseph de Caldas, individuo meritorio de la Expedición Botánica de Santafé de Bogotá, y encargado del Observatorio Astronómico de esta capital”, en Semanario del Nuevo Reyno de Granada, número 22, Santafé de Bogotá, 29 de mayo de 1808, p. 258, e Hipolito Unanue, Observaciones sobre el clima de Lima y sus influencias en los seres organizados, en especial el hombre, Lima, Imprenta Real de los Huérfanos, 1806.
} 


\section{El trópico caribeño}

Aun cuando en el caso de las Islas Bermudas, Clark entendía que era improbable que estas se convirtieran en un resort of invalids, dada su distancia de Inglaterra, convenía, sin embargo, en que:

Provided, however, that domestic circumstances rendered Bermuda a convenient residence, invalids might pass the winter there safely, and perhaps with benefit. There are many beautiful spots in these islands, where, protected from the northerly gales by the cedar-clothed hills, the invalid might find sufficient space to enjoy exercise in the open air, almost every day during the winter ${ }^{8}$.

\section{Igualmente, en relación con Bahamas, Clark sostuvo:}

... it appears evident that the Bahama Islands are not well calculated for the generality of invalids. The climate is not suited for consumptive patients, on account of the rapid changes of the temperature, and the prevalence of winds, often of a dry, cold character. At the same time persons, for those cases a warm climate is indicated, may pass the winter in the Bahamas safely; and residents in the West Indies might derive considerable benefit by a change to these islands for a few months during this season ${ }^{9}$.

Por su parte, sobre el resto de islas consideradas como West Indias, Clark hizo un análisis pormenorizado de las observaciones y cálculos científicos que otros galenos habían llevado a cabo en dichas islas, concluyendo a la postre lo siguiente:

I consider it necessary to notice the West India Islands, because they are occasionally recommended as a winter residence to patients labouring under pulmonary and some other chronic diseases; and because their climate, either as regards its physical character or its influence on disease, does not seem to be generally known or understood by medical men in this country ${ }^{10}$.

En otras palabras, por fuera de la buena voluntad y los deseos de los médicos por querer encontrar en estas islas caribeñas un espacio para el mejoramiento de sus pacientes, Clark concluía que estas no eran del todo adecuadas para tal efecto:

\footnotetext{
${ }^{8}$ J. Clark, The sanative influence, p. 148. Provisto, sin embargo, que las circunstancias domesticas rinden en Bermuda una residencia conveniente donde los enfermos podrían pasar un invierno seguro allí y tal vez con beneficios. Hay muchos sitios hermosos en estas islas, protegidas de los vientos del norte por las colinas. Los enfermos podrían encontrar suficiente espacio donde disfrutar de ejercicios al aire libre casi cada durante el invierno. Nota: Esta y todas las demás traducciones son mías.

9 J. Clark, The sanative influence, p. 149. Parece evidente que las Bahamas no han sido bien calculadas para todos los enfermos. El clima no es adecuado para pacientes consuntivos, por cuenta de los cambios rápidos de temperatura y la prevalecencia de vientos, con frecuencia de carácter frio y seco. Al mismo tiempo, personas para cuya condición se ha indicado los climas cálidos, pueden pasar el invierno en las Bahamas con seguridad, y los residentes de las Indias Occidentales podrían derivar beneficios considerables al mudarse a estas islas por algunos meses durante esta estación.

10 J. Clark, The sanative influence, p. 150. Considero necesario advertir sobre las Indias Occidentales, porque son ocasionalmente recomendadas como residencia de invierno a pacientes con afecciones pulmonares y algunas otras enfermedades crónicas, y porque su clima, bien sea por su carácter físico o por su influencia en la enfermedad, no parece ser generalmente conocido o entendido por los médicos en este país.
} 
The cases of Pulmonary Consumption, therefore, in which the climate of the West Indies promises advantage are very few, and their character scarcely ascertained; while those in which it produces mischief are numerous, and generally well-marked. Of persons predisposed to the disease, a certain proportion are likely to be benefited by the climate, -but the nature of the constitution should be well considered before it is recommended even as a prophylactic ${ }^{11}$.

De esta manera, el trópico, considerado en las reflexiones de no pocos naturalistas y científicos, además de experimentados viajeros de los siglos XVIII y XIX, como un espacio donde el hombre nada podía hacer frente a la fuerza de la naturaleza, sino abandonarse enteramente a esta, por lo cual sus comportamientos y desmanes eran la evidencia palpable de que el trópico era el límite entre lo civilizado y el universo de lo bárbaro; la posible ampliación de sitios, que para este caso se trataba de algunas islas en el Caribe, quedaba prácticamente excluida de las pretensiones de aquellos interesados en recomendar a sus necesitados pacientes, mejores condiciones climáticas y sanitarias.

Sin embargo, más allá de los estudios sobre climatología tropical, la zona geográfica iría poco a poco adquiriendo importancia y se convertiría, súbitamente en un espacio cuyas fuerzas podían contribuir al beneficio del hombre civilizado, si se controlaban adecuadamente. En 1898, año de la Guerra Hispano Americana y de la invasión de Puerto Rico por parte de los Estados Unidos, Benjamin Kidd, considerado uno de los padres fundadores de la sociología, y quien se hizo muy famoso por la publicación de su ensayo Social Evolution ${ }^{12}$, publicó un libro llamado The control of the tropics ${ }^{13}$, en el que daba por sentado que el trópico le pertenecía como herencia a la civilización occidental y que, dada su superioridad organizativa sobre las otras razas ${ }^{14}$, el hombre blanco debía controlarlo:

The events of real importance, those which are destined to shape and control the tendencies of history into the distant future, are those connected with the struggle for, and the occupation by the winning sections of the Western peoples of, these regions of the world where the white races can live permanently and work. (...) The great rivalry of the past has been

\footnotetext{
${ }^{11}$ J. Clark, The sanative influence, p. 155. Los casos de consunción pulmonar, por lo tanto, en los cuales el clima de las Indias Occidentales promete avances son muy pocos, y su alcance apenas comprobado, mientras en aquellos en los que produce desordenes son numerosos, y generalmente bien marcados. Sobre personas predispuestas a la enfermedad, cierta proporción es probable que se beneficie del clima, pero la naturaleza de su constitución debería ser bien considerada antes que se recomiende incluso como profiláctico.

${ }^{12}$ Benjamin Kidd, Social Evolution, London, Macmillan and Co., Limited, 1906, The control of the tropics, New York, The Macmillan Company, 1898. La primera publicación se hizo en 1894. En este libro Kidd aplicó ideas de biología evolutiva a la evolución de las sociedades.

13 B. Kidd, The control of the tropics. La primera publicación se hizo en 1894. En este libro Kidd aplicó ideas de biología evolutiva a la evolución de las sociedades.

${ }^{14}$ Estudios recientes en antropología son claros en identificar que las razas no existen como categoría de análisis social, dado que los humanos se agrupan como especie, por la tanto, las etnias serian la mejor forma de identificar sus diferencias, si se sigue el orden taxonómico. A nivel biológico, la diferenciación es todavía más problemática, dado que las variaciones genéticas son prácticamente inexistentes. Sin embargo, como categoría histórica, el concepto raza, sigue teniendo validez, máxime cuando la gran mayoría de la población mundial sigue pensando en términos de raza. Al respecto véase a: Peter Wade, Degrees of Mixture, Degrees of Freedom: Genomics, Multiculturalism, and Race in Latin America, Durham, Duke University Press, 2017. Una prueba de que el asunto de la cuestión racial sigue estando presente en las discusiones globales se encuentra en Nicholas Wade, Una herencia incomoda. Genes, raza e historia humana, Barcelona, Ariel, 2015.
} 
determined -decided on the whole overwhelmingly in favour of the English-speaking peoples. It has been for the inheritance of the white man's land of the world. The great rivalry of the future is already upon us. It is for the inheritance of the tropics, not indeed for possession in the ordinary sense of the word, for that is an idea beyond which the advanced peoples of the world have moved, but the control of these regions according to certain standards ${ }^{15}$.

Nada raro, por tanto, aunque Kidd argumentara que la posesión del trópico no fuera el objetivo final, tampoco cuestionara las acciones norteamericanas con claros intereses imperialistas en el Caribe. Se creía, por entonces, que el trópico debía ser dejado a su suerte, pero Kidd opinaba lo contrario, ya que observaba en su libro con especial detenimiento, cómo la dependencia de productos tropicales iba cada vez en aumento en Europa y Estados Unidos. De ahí el interés creciente:

If we turn at the present time to the import list of the world and regard them carefully, it will soon become apparent to what a large extent our civilization already draws its supplies from the tropics. Of recent years we have been largely occupied in discussing questions affecting of our industrial production. Yet it is curious to reflect to what large extent our complex, highly organized modern life rest on the work and production of a region of the world to which our relations are either indefinite or entirely casual; a region which has, it must be remembered, hitherto produced no example of native government successful in the European sense $(\ldots)^{16}$.

El trópico, esa zona geográfica del planeta ubicada entre los paralelos 30 norte y 30 sur, fue considerada durante largo periodo de tiempo, como un espacio del que había que alejarse lo más que se pudiera, si se deseaba gozar de buena salud corporal y mental. De esta manera, -siguiendo a Kidd-, si la balanza de importaciones aumentaba, y con ello la dependencia de los civilizados sobre aquellos que no podían si quiera gobernarse a sí mismos, ¿por qué mantener unas relaciones desventajosas, cuando se podía ejercer sobre esos espacios un nivel de control acorde con estándares europeos de sujeción? En 1880, Wolfred Nelson, un medical practitioner ${ }^{17}$ quien a su vez era corresponsal del periódico canadiense The Gazette, y quien estuvo viviendo en Panamá durante cinco años, sostuvo:

\footnotetext{
${ }^{15}$ B. Kidd, The control of the tropics, p. 3. Los eventos de real importancia, aquellos destinados a controlar y dar forma a las tendencias históricas del futuro lejano, son aquellos conectados con la lucha por, y la ocupación por las secciones triunfantes de los pueblos occidentales, de aquellas regiones del mundo donde la raza blanca pueda vivir y trabajar permanentemente... La gran rivalidad del pasado ha sido determinada -decidida en general abrumadoramente en favor de la gente de habla inglesa. Ha sido por la herencia del hombre blanco de la tierra del mundo. La gran rivalidad del futuro esta sobre nosotros. Es por la herencia del trópico, de hecho no por la posesión en el sentido ordinario de la palabra, porque esa es una idea más allá de la cual las personas avanzadas del mundo se han movido, sino por el control de estas regiones, de acuerdo con ciertos estándares.

${ }^{16} \mathrm{~B}$. Kidd, The control of the tropics, p. 5. Si miramos en la actualidad la lista de importaciones mundiales y las consideramos cuidadosamente, pronto se hará evidente hasta qué punto nuestra civilización sustrae sus suministros desde los trópicos. En años recientes hemos estado en gran parte ocupados discutiendo asuntos relacionados con las condiciones que afectan nuestra propia producción industrial. Sin embargo, es curioso el reflejo del nivel en el cual nuestra compleja y altamente organizada vida moderna, descansa en el trabajo y producción de una región del mundo con respecto a la cual nuestras relaciones ni son indefinidas ni enteramente casuales. Una región que, hay que recordarlo, hasta ahora no producido un ejemplo de gobierno nativo exitoso en el sentido europeo.

${ }^{17}$ Es lo que en nuestro tiempo se identifica como un estudiante residente, es decir, antes de obtener el título como médico.
} 
There is a general believe held by many highly intelligent people that a residence within hot countries has a market tendency to increase the sexual instincts. Such is not the case. The real explanation of it is this. The majority are away from the refining influences of the early culture and home life, -generally they are single man, - in a warm climate where all the conditions are supposed to produce general relaxation. There is a little society open to such men ${ }^{18}$.

Por lo tanto:

The moral of all this is: keep out of the tropics if you can. Should necessity force you within then avoid all forms of alcohol, that you may spend your later days in peace and conford. Anyone who has travelled extensively in the tropics, -I refer to the West Indies and the tropical portions of Central and South America-, can tell you of dozen of noble young fellows who have been wrecked almost of the outset by the relaxation, which ignorant people charge to the effects of the climate, instead of attributing it to the bad associates; wine and women. The climate is no responsible; the mortality is due to the want of firmness and those corrective influences so necessary for the best of us ${ }^{19}$.

Si el clima no era la razón por la cual aquellos solteros que se atrevían a visitar el trópico de este lado del mundo, terminaban, -de acuerdo con Nelson-, en malas compañías, y siendo víctimas del alcohol y las mujeres, entonces ¿de dónde sacaba este autor la idea de que todo en los países cálidos estaba dispuesto para la relajación?

\section{El asunto de la salud y la nutrición en Europa}

La Europa del siglo XVII conoció el hambre como nunca antes, hambre que golpeó al viejo mundo una y otra vez, a lo largo de toda la centuria: 1630, 1649, 1661 y 1664; causando cientos de miles de muertes. Las fuertes nevadas y el desconocimiento de métodos agrícolas alternativos, como la rotación de cultivos, hacían fuerte mella en la obtención de productos agrícolas suficientes para cubrir las necesidades de la mayoría. Con las hambrunas, las enfermedades tampoco se hicieron esperar y factores como el fuerte hacinamiento en los espacios urbanos, los escasos conocimientos acerca de la transmisión de enfermedades infecto-contagiosas y los inexistentes servicios sanitarios, contribuyeron a que el siglo fuera uno de los más desoladores en la historia del antiguo continente.

\footnotetext{
${ }^{18}$ Wolfred Nelson, Five years at Panama. The trans-isthmian canal, New York, Belford Company Publishers, 1889 , p. 17. Hay una creencia general sostenida por gente muy inteligente, es que residir en países calientes tiene una tendencia marcada a incrementar los instintos sexuales. Ese no es el caso. La explicación real es esta: la mayoría están lejos de las influencias de su cultura y hogar -generalmente son hombres solteros-, en un clima cálido donde todas las condiciones están supuestas para producir relajación general. Hay una pequeña sociedad abierta a tales hombres.

${ }^{19}$ N. Wolfred, Five years at Panama, p. 19. La lección de todo esto es: mantente alejado del trópico si puedes. Si te ves forzado por necesidad dentro de ellos, evade todas las formas de alcohol, así podrás estar los últimos días de tu vida en comodidad y confort. Cualquiera que ha viajado ampliamente en el trópico, -me refiero a las Indias Occidentales y la parte tropical de América Central y del Sur-, puede contarle de docenas de jóvenes que han sido destruidos casi desde el principio por la relajación, lo cual la gente ignorante atribuye al clima, en vez de culpar a las malas compañías, al vino a y a las mujeres. El clima no es responsable; la mortalidad se debe a la falta de firmeza y a esas influencias correctivas tan necesarias para nuestro bienestar.
} 
La práctica médica era escasa, como escasos eran los conocimientos sanitarios de la época: pueblos enteros no tenían médicos y la labor era llevada a cabo en muchos casos por barberos y curanderos. Los primeros llevaban a cabo sangrías, además de extraer dientes y curar pequeñas heridas, mientras los segundos parecían obtener sus conocimientos de costumbres y rituales antiguos. Entre los barberos y los curanderos se cubría la demanda de cuidado médico que, debido a la ausencia de galenos o al costo de sus servicios, no podían obtener las masas ${ }^{20}$.

La valiosa aportación que un trabajo de tanta referencia académica, como lo es la Historia de la Vida Privada de Phillipe Aries y George Duby ${ }^{21}$, estriba en que su lectura nos lleva a un universo histórico no conocido sobre el viejo continente: edificaciones cuyo interior estaba cubierto por hollín que ennegrecía las paredes, como resultado de la no existencia de separación de espacios, mientras el frio exterior obligaba a cocinar dentro de los hogares, dando como resultado uno de los problemas más acuciosos de la Europa de los siglos XVII y XVIII: los problemas respiratorios. De hecho, aun durante el siglo XIX, las enfermedades respiratorias eran la causa del mayor número de muertes, aun por encima de la sífilis y el cáncer ${ }^{22}$.

Si bien el siglo XVII fue difícil para la mayoría de la población europea, en algunos círculos exclusivos se empezaron a llevar a cabo prácticas modernas que hoy conocemos como ocio y turismo. Aunque su origen no es el siglo XVII, sino mucho antes. Es a finales de ese siglo cuando se retoman prácticas abandonadas durante la Edad Media. Así, el Renacimiento dio paso a la proliferación de ilustrados que divulgaban ideas no tan nuevas ${ }^{23}$, pero si revolucionarias para la época, en especial, aquellas que planteaban un rompimiento con las ideas que sugerían estados deprimidos del cuerpo debido al castigo divino por errores o pecados cometidos. No fueron, por tanto, gratuitas la implementación y desarrollo de estaciones balnearias en los países europeos inicialmente mencionados; igualmente, las alteraciones en el comportamiento de las élites francesas, quienes gustaban de retiros veraniegos, introdujeron a su vez cambios en las élites y clases acomodadas de España a principios del siglo XVIII ${ }^{24}$.

Para hacer notar la preocupación que generaba en los círculos académicos el asunto del clima frio y los problemas respiratorios, baste con citar las opiniones de Gabriel de Belcastel, prolífico escritor francés de mediados del siglo XIX, quien, debido a la enfermedad respiratoria de una de sus hijas,

\footnotetext{
${ }^{20}$ Al respecto véanse a: Pedro Lain Entralgo., Historia de la Medicina, Barcelona, Salvat Editores, 1978; Charles Singer y Underwood, E. Ashworth: A short history of Medicine, Oxford, Clarendon Press, 1962.

${ }^{21}$ Phillipe Aries y George Dub, "El proceso de cambio en la sociedad de los siglos XVI-XVIII", en Historia de la Vida Privada, Tomo 5, Madrid, Taurus, 1992; Alain Corvine, Jean Jacques Courtine y Georges Vigarello, Historia del Cuerpo, vol. 1, Madrid, Taurus, 2005 ,

${ }^{22}$ Cristina de Iriarte y Clara Curell, Introducción a La Orotava y la magia de su clima de Gabriel de Belcastel, Santa Cruz de Tenerife, Ediciones Idea, 2004.

${ }^{23}$ N. Gonzalez L., Clima y medicina, plantea que ya Hipócrates sugería una relación intrínseca entre clima y enfermedades y que fue Paracelso quien en el siglo XVII retoma esas ideas y las difunde en la Europa ilustrada.

${ }^{24}$ Mónica Bolufer, Mujeres e Ilustración. La construcción de la feminidad en la España del siglo XVIII, València, Instituciò Alfons el Magnànim, 1998.
} 
visitó varios lugares en Europa, gastando parte de su fortuna, tratando de encontrar un espacio adecuado para su recuperación. En 1861, luego de visitar las Islas Canarias, publicó un libro en el que expresaba con claridad el asunto:

Existe un enemigo que tal vez sea el único al que todos y en todas partes odiamos y combatimos de forma unánime, al que ninguna traición ni complicidad voluntaria abren la puerta y cuyo aniquilamiento persiguen, con incesante ardor, todos los dictados aliados de la ciencia, del arte, del talento y del amor, un enemigo que lucha sin tregua por la consecución de sus triunfos: me refiero a la enfermedad ${ }^{25}$.

Pero no era cualquier enfermedad la que le preocupaba:

Dentro del inmenso ejército de las enfermedades, hay una que, por si sola y debido a sus múltiples grados, formas, e incluso nombres, podría considerarse una legión. El único rasgo que presenta en común consigo misma es que ataca las vías respiratorias. En ocasiones, condena a un prolongado mutismo al hombre que ha entregado su vida a cultivar la palabra; en otras, cubre con un velo de languidez lo más amable y puro del mundo, la frente de las dulces muchachas, flores de la tierra y del cielo. A veces grave y otras leve, pero siempre molesto, envenenando a menudo la vida que no llega a amenazar, este mal, con todos sus matices, es el azote del norte ${ }^{26}$.

Así, Belcastel, en compañía de Clark y otros escritores y científicos de su época, allanaron el camino para que las Islas Canarias adquirieran la fama de ser el mejor clima del mundo en el siglo XIX.

\section{Islas subtropicales o islas paraíso}

En 1837, William Wilde, padre de Oscar Wilde, un médico irlandés que había alcanzado reputación como cirujano, visitó las islas de Madeira y Tenerife en su periplo por el Mediterráneo. Producto de sus observaciones durante su largo viaje $\mathrm{e}^{27}$, nació su defensa del clima beneficioso de Canarias, especialmente del Valle de La Orotava en Tenerife; para el mejoramiento de las condiciones de salud de los pacientes con dificultades respiratorias. En sus memorias de viaje, publicadas más tarde en dos volúmenes, confirmaba lo que unos años antes otro médico británico ya había observado, medido y cuantificado:

On the characteristics of climates in reference to disease, little has been added in our stock of information, since the publication of Sir James Clark's work, which, moreover, did not touch upon those shores of the

\footnotetext{
${ }^{25}$ Gabriel de Belcastel, Les Iles Canaries et la vallee d'Orotava au point de vue hygienique et medical, Paris, J. B. Bailliere et Fils, 1861, p 29. Existe traducción al Español: Las Islas Canarias y el Valle de la Orotava bajo el punto de vista médico e higiénico, Santa Cruz de Tenerife, Imprenta y Litografia Isleña, 1862.

26 G. de Belcastel, Les Iles Canaries et la valle, p. 30.

27 Wilde William R., Narrative of a Voyage to Madeira, Tenerife and along the shores of the Mediterranean, Dublin, William Curry, Jun and Company, 1840. Two Volumes.
} 
eastern extremity of the Mediterranean, which it was my fortune to visit. Of Madeira and the Canaries, I feel that too much cannot be said; and upon comparing my own notes with the opinions and investigations of others, I am daily more convinced that for invalids they are vastly superior to any other climate within the same distance of our shores. I trust, that persons in search of health will glean from my pages some useful information relate to the accommodations and best seasons for visiting the various places we touched at, in the Levant, and elsewhere ${ }^{28}$.

Wilde buscaba así hacerse también con un espacio propio dentro de las discusiones sobre clima y salud. No es fortuito leer en sus palabras, el vacío que, en su opinión, había dejado Clark, al no visitar la parte oriental extrema del Mediterráneo, parte que Wilde sí incluía. Se podría, por tanto, afirmar que Wilde completó con sus observaciones, mediciones y escritos, el trabajo que Clark había iniciado unos años antes. Más aún, mientras Clark se dedicó a mediciones del clima en varios lugares de la isla, Wilde sacó conclusiones acerca de los futuros beneficios para afecciones médicas:

En mi opinión, el clima de esta isla no es de ninguna manera inferior al de Madeira y no tengo dudas de que es mucho más seco. Durante nuestra estancia el termómetro subió a unos $72^{\propto}$ durante el día. Dos observaciones hechas con el hidrómetro dos días distintos señalaron el punto de rocío en 410 , termómetro $75^{\dagger}$, dando $34^{\circ}$ de sequedad, un estado solo observado una vez por el Dr. Heineken durante una estancia de nueve años en Madeira (...) Creería que este clima es admirablemente apropiado para las afecciones bronquiales con mucha expectoración, o para esos estados de aflojamiento de membrana mucosa de la garganta y la fauces, tan común entre nosotros desde hace unos años, así como las secuelas diftéricas y otras afecciones similares, o las que les ocurren a las personas que padecen de tener que hablar mucho en público, cantar, etc., en que las partes afectadas se aflojan bastante ${ }^{29}$.

Si bien es el trabajo de Clark el que le da un impulso de peso científico a las concepciones sobre el clima de las islas, él no fue el primero en anunciarlas.

Ya George Glas, un practicante médico, viajero y comerciante irlandés quien visitó y vivió en las Islas Canarias, a mediados del siglo XVIII, lo anotaba como un aspecto sobresaliente del archipiélago: The climate of those islands is exceeding wholesome, which may be owing to the drinels of the soil and the strong northerly wings that almost continually blow upon them, so that

\footnotetext{
${ }^{28}$ Wilde William R., Narrative of a Voyage to Madeira. Sobre las características del clima en relación con las enfermedades, poco se ha podido agregar a nuestro acervo de información desde la publicación del trabajo del señor James Clark, quien, además, no llego a las costas de la extremidad este del Mediterráneo, las cual estuve la fortuna de visitar. De Madeira y de Canarias, siento que no hay mucho que decir y al comparar mis notas con las investigaciones y opiniones de otros, estoy cada día más convencido que para los enfermos, el suyo es bastante superior al de cualquier otro clima dentro de la misma distancia de nuestras costas. Confío que personas en búsqueda de salud, puedan hojear en mis páginas alguna información útil relacionada con alojamiento y las mejores estaciones para visitar varios lugares que tocamos en el levante y en otras partes.

${ }^{\circ} 72$ G.F. $\left(22,2^{\circ}\right.$ C). Nota en el original.

$\dagger+75$ G.F. $\left(23,9^{\circ} \mathrm{C}\right)$. Nota en el original.

29 Wilde William, Narración de un viaje a Tenerife, Santa Cruz de Tenerife, Ediciones Idea, 2004, p. 53. Esta publicación es una extracción al español de la versión original publicada en 1840 y recoge solo la parte correspondiente al viaje del escritor en territorio canario.
} 
the inhabitants in general live to a great age, ${ }^{30} \mathrm{y}$ seguramente habrá que indagar en los archivos del siglo XVIII para descubrir otros viajeros anteriores a Glas, que afirmaron lo mismo ${ }^{31 .}$

Esta longevidad de los habitantes canarios, cuya fuente encontraba Glas en las bondades del clima, las apuntalaba con una buena dosis de productos del campo:

As to fruits, here the almond, walnut, chesnut, apple, pear, peach, apricot, cherry, plum, mulberry, fig, banana, date, orange, lemon, citron, lime, pomegranate, and in short all the American and European fruits, except anana, or pine-apple, of which I think there are none in these islands. Of grain they have wheat, barley, and maize or Indian corn; put peas, beans, and garravansas ${ }^{*}$ are scarce and dear: melons of different sorts, potatoes, batatas, yams, pompions, best onions in the world, and many other kinds of roots are found in plenty here, and all good in their kind: cabbages and fallads are not wanting. In short, in all the Canary Islands westward of Fuertaventura, nature amply rewards the labourer for his toil in cultivating the ground ${ }^{32}$.

Incluso, aun reconociendo la aridez de algunas de las islas que conforman el archipiélago, Glas, al entrar en contacto con espacios donde era más propicio el crecimiento de vegetación, confirmaba sus sospechas: "Hitherto I have been describing the islands that are almost deserts when compared with the fertile and pleasant one of Canaria, which, for the excellent temperature of its air, and the plenty of good water, trees, herbs, and delicious fruits that are found thereon, well deserves the name of the Fortunate Island" 33 . Sin embargo, a diferencia de las posturas sobre el clima, a las que llegaron Clark

\footnotetext{
${ }^{30}$ George Glas, The history of the discovery and conquest of the Canary Islands, Dublin, Printed for D. Chamberlaine, 1764, p. 194. El clima de estas islas es muy saludable, lo cual podría deberse a la sequedad de la tierra y a fuertes vientos del norte que casi continuamente sopla sobre ellas, de esta forma, sus habitantes en general viven hasta gran edad.

${ }^{31}$ Prácticamente todos los viajeros que incluyeron antecedentes históricos sobre las Islas Canarias, hacen referencia al conocimiento que los pueblos antiguos tenían acerca de la existencia de las islas, y en nombres como Jardin de las Hesperides o también Islas Afortunadas, se repite. Por citar un ejemplo, al británico Richard F. Burton, famoso por sus viajes al lejano oriente, quien en su descripción de un día en Tenerife, escribió:

Desde los tiempos más remotos, estas (...) -islas de la macaronesia- han sido un tema de comentario entusiasta; y aquí puedo observar que aunque las Islas Afortunadas no son peculiarmente felices, podrían, con cuidado y cultura, convertirse en un Elíseo terrenal. Plutarco describe así al archipiélago: "La tierra es tan abundantemente fértil, que produce espontáneamente plantas y frutas, para uso y disfrute, suficiente para responder a las necesidades y deleitar el paladar de los habitantes". Del clima, el observa "se cree firmemente, incluso por los mismos nativos bárbaros, que esta es la mansión de los bienaventurados". M. Bory de St. Vincent, en sus "Essais sur les iles Fortunees" descubre en Tenerife y sus vecinas islas, el auténtico Monte Atlas de Homero; y Virgilio, el jardín de las Hespérides con sus manzanas doradas, las Gorgonas bajo la Reina Medusa, los campos Elíseos, las islas Purpúreas, la Atlántida de Platón y la cuna de ese pueblo atlántico, las cuales fueron aniquiladas subsiguientemente por temblores de tierra, los volcanes y las erupciones del mar (...).

En: Richard F.Burton. Mis viajes a las Canarias, Edición y estudio introductorio de Nicolás González Lemus. La Laguna, Tenerife, Nivaria Ediciones, 2004, p. 97.

**A kind of horse-beans, written generally Caravancas. (Un tipo de habas escritas generalmente como Caravancas). Nota en el original.

${ }^{32}$ G. Glas, The history of the discover, p. 230. En cuanto a las frutas, aquí hay nuez, castaña, manzana, pera, melocotón, albaricoque, cereza, ciruela, mora, higo, banana, naranja, limón, cidra, lima, granada, y, en resumen, todas las frutas americanas y europeas, excepto ananá o piña, la cual creo que no existe ninguna en estas islas. De los granos, tienen trigo, cebada y maíz o maíz de las indias, frijoles y habas son escasos y apetecidos; melones de diferentes géneros, batatas, pompones, las mejores cebollas del mundo y muchos otros tipos de raíces se encuentran en abundancia aquí: y todo bueno en su tipo: repollo y coles no se buscan. En resumen, en todas las islas canarias, al oeste de Fuerteventura, la naturaleza recompensa ampliamente al trabajador por su esfuerzo al cultivar la tierra.

${ }^{33} \mathrm{G}$. Glas, The history of the discovery, p. 224. Hasta ahora he estado describiendo las islas que son casi desérticas cuando se comparan con la fértil y agradable Canaria, la cual, por la excelente temperatura de su aire y la cantidad suficiente de agua, árboles, hierbas y frutos deliciosos que se encuentran en esta, bien merece el nombre de la Isla Afortunada.
} 
y Wilde, que, dados los avances tecnológicos de la época, concluyeron como resultado de cálculos y medidas meticulosamente llevadas a cabo por ambos; -con instrumentos que Glas seguramente no poseía, porque no existían-, el cirujano y capitán de navío consideraba que Gran Canaria tenía el mejor de todos: The temperature of the air is no where more delightful than in the island of Canaria ${ }^{34}$.

Más de cien años después, John Whitford, quien fuera miembro de la Real Sociedad Geográfica Británica, recomendaba hacer el esfuerzo de rentar una casa en La Orotava en plan familiar, para disfrutar del apacible clima de las islas:

El alquiler de una residencia durante todo el invierno, para toda una familia, incluyendo el precio del pasaje transoceánico, no representa una inversión mayor que la necesaria para pasar idéntico tiempo en el gélido hogar, inclusive si este dispone de los medios más modernos que impiden sentir los efectos del aire frío en el interior. Al escribir esto, me dirijo a aquellas personas, sensatas, que pueden permitirse esas pequeñas comodidades sin que les ocasione algún apuro económico, a aquellos bendecidos por la diosa de la Fortuna, a aquellos para los que el coste de la vida es indiferente ${ }^{35}$.

Whitford conocía perfectamente las condiciones económicas de la mayoría de los ingleses. No era a ellos a los que les escribía una carta abierta en el periódico local donde le publicaban las misivas que llegaban desde las islas durante el tiempo de su estancia. Consciente de su condición social, pero aún más consciente de sus propios males, convenía en recomendar que aquellos que pudiesen escapar a la frialdad del invierno, hicieran el esfuerzo de disfrutar sin mayor preocupación una estancia en el paraíso.

Ese mismo paraíso es el que leyó anunciado Isaac Latimer a finales del siglo XIX en algún lugar de Inglaterra y quien lo dejó claro en su escrito:

En primer lugar, fuimos atraídos por Tenerife por la lectura de un folleto publicado por una compañía inglesa sobre un hotel que funcionaba en el Puerto de La Orotava, en el que se decía que allí en el mes de marzo, son desconocidos los vientos de este y que existe una gran uniformidad en el clima, tan templado, agradable y encantador como para hacerlo bastante preferible, para los que sufren alguna enfermedad del pecho, a cualquier lugar de las playas más conocidas de la Riviera. La compañía hotelera de la que hablo había alquilado la residencia de la viuda de un difunto caballero y la había acondicionado para los gustos ingleses; y en su cuisine, entretenimientos y ambiente, era el beau ideal para las necesidades de un inglés cuando éste se encuentra en un sanatorio, o cuando está dispuesto a disfrutar de la tranquilidad y la puede encontrar junto a una refinada y agradable sociedad ${ }^{36}$.

\footnotetext{
${ }^{34} \mathrm{G}$. Glas, The history of the discovery, p. 229. No hay un lugar con la temperatura más agradable que en la isla de Canaria.

35 John Whitford, The Canary Islands as a winter resort, London, Nabu Press, 1890, p. 65.

${ }^{36}$ Isaac Latimer, Notas de un viaje a las islas de Tenerife y Gran Canaria. Un clima de verano en invierno, La Orotava, J.A.D.L editores, 2002, p. 37.
} 
A finales del siglo XIX, aquellos que tenían la posibilidad de leer directamente de quienes habían viajado y publicado sus memorias de viaje, o bien tener acceso a los folletos que menciono Latimer, podían contrastar lo narrado con la realidad, pero, sobre todo, viajar a intentar curarse de sus afecciones, lo cual era en si un privilegio reservado a unos pocos:

Los libros acostumbran a decirnos que el viaje a La Laguna es árido y que luego la isla se vuelve sumamente atractiva. A nosotros no nos pareció así. Disfrutamos del paisaje durante todo el trayecto. Por todos sitios el campo parecía casi tan verde, en muchas comarcas tan verde, como la isla Erin, mientras que todo indicaba que nos encontrábamos cerca del trópico. Había palmeras de diferentes especies, plataneras, naranjos, higueras, moreras, castaños, una gran variedad de otros árboles y flores en abundancia, de las que muchas solo se pueden ver en Inglaterra creciendo en invernáculos; y había miles de terrazas cultivadas, en las que los isleños hacen su trabajo agrícola $^{37}$.

y al mismo tiempo podían darse a la tarea de verificar lo descrito y maravillarse. Así describió Olivia Stone, una viajera británica, su primera impresión al visitar Tenerife:

The "Valley" is so luxuriant, that the whole appears a tangled mass of orange groves, banana trees, vineyards, olives, mangoes, guavas, and every conceivable fruit and vegetable that the heart of man can desire. The usually ugly, flat-roofed houses are here covered, gracefully festooned, and hidden by lovely flowering keepers. We had one pleasure derived from knowledge, and therefore appealing to the reason, not the senses, that made us contemplate El Valle with satisfaction. It is considered by all authorities-English, French, German, Swedish, and Spanish-to be without exception the healthiest place on the face of the globe. The Canarian Archipelago rejoices in the most magnificent climate in the world, and Orotava is the most excellent of the excellent. Many surpass it in beauty, some possibly in health, as Arrecife, in Lanzarote, nut none combine health, beauty, and convenience in so favoured a degree as Orotava. No wonder Bencomo strove h.ard for his inheritance and fought for Orotava! ${ }^{38}$.

De esta manera, la comprobación de lo leído en lecturas anteriores al viaje, se convierte, en palabras de Olivia Stone, en la verificación racional, no sensitiva, de que, en efecto, La Orotava, en Tenerife, tenía el mejor clima del mundo; pero el placer de contemplar y disfrutar del clima y los espacios que ofrecía La Orotava en el momento de la observación, no desaparecía. Estaba,

\footnotetext{
37 I. Latimer, Notas de un viaje, p. 39.

${ }^{38}$ Olivia Stone, Tenerife and its six satellites or the Canary Islands past and present, London, Marcus Ward \& Co. Limited, 1889 , p. 37. El "valle" es tan exuberante, que todo aparece como una masa enredada de naranjos, arboles de bananos, viñedos, aceitunas, mangos, guayabas y cada fruta y vegetal concebible que el corazón de un hombre pueda desear. Las usualmente feas casas de techos planos, están aquí cubiertas, graciosamente festivas y ocultas por encantadores protectores florales. Tuvimos un placer derivado del conocimiento, y por lo tanto, más razonado, no de los sentidos, que nos hizo contemplar el valle con satisfacción. Es considerado por todas las autoridades inglesas, francesas, alemanas, suizas y españolas, de ser, sin excepción, el lugar más saludable en la superficie terrestre. El archipiélago canario se regocija en el clima más magnífico del mundo y Orotava es lo mejor de lo mejor. Muchos le superan en belleza, algunos, posiblemente en salud, como Arrecife, en Lanzarote, pero ninguno combina salud, belleza y conveniencia en el grado favorable de Orotava. Nada raro que Bencomo se esforzó por su herencia y luchó por Orotava.
} 
de hecho, presente en sus descripciones, aun cuando se acudiera a la explicación racional de la experiencia:

There is this to be said for Orotava: that, everything being taken into consideration-its position, climate, surroundings, habitations, society, conveniences, and, above all, proximity to the Peak-it is the most suitable spot in the archipelago as a residence for foreigners. It would not be doing Orotava justice to say that it will shortly be a second Funchal, for it can easily rival, and must certainly surpass, Madeira as a winter residence for invalids, besides having attractions that will induce the healthy to resort thither and prevent it from ever becoming the melancholy hospital that Funchal is ${ }^{39}$.

Y tal como le he afirmado antes, Stone no fue, ni mucho menos, la única que contó para occidente las bondades del clima de La Orotava. Elizabeth Murray, otra viajera británica que estuvo viviendo durante más de una década en un triángulo comprendido entre Canarias, Madrid y Marruecos, narró en sus relatos de viaje lo vivido:

A menudo he mencionado la vista, desde diferentes puntos del Valle de La Orotava. Desde cualquier lugar lo encontramos siempre hermoso; cada vez impresiona más por su incomparable belleza. (...) No intentaré describirlo, solo repetiría lo que ya he dicho en anteriores ocasiones: incluso la palabra más exacta quedaría corta ante su trascendental belleza. (...) todo lo que puedo decir es que es hermoso y encantador. Un espectáculo tan brillante, resplandeciente y soleado como este, no se podría encontrar en la faz de la tierra, ?dónde se podría ver tal combinación de los atributos de la naturaleza con su variedad de flores, los arboles con su alegre follaje, las esmaltadas laderas con sus pueblos y aldeas surgiendo aquí y allá entre bosques y jardines y las espirales de las iglesias resplandeciendo bajo los brillantes rayos de un día soleado? Desde la cima en que me encontraba, observamos los campos de trigo, con su rica cosecha de grano dorado; los viñedos con sus maduros racimos de exquisita uva y las tranquilas ermitas enramadas entre las hojas y bajo la sombra de la abundante hojarasca del Drago o de la palmera ${ }^{40}$.

Ahora bien, esta abundancia vegetal de la que hablaban Olivia Stone y Elizabeth Murray, no se parecía a la complejidad y la exuberancia del trópico que había encontrado Eliseo Reclus en su viaje de Panamá a Cartagena:

Desde la cima hasta el pie de las colinas, no se ve sino un tumulto, un océano de follaje, bajo esa masa que se inclina y se levanta al soplo de los aires, apenas puede concebirse el suelo que las sostienen; fácilmente podría creerse que la selva entera tiene sus raíces en el mar y que flota sobre las

\footnotetext{
${ }^{39}$ O. Stone, Tenerife and its six satellites, p. 29. Hay que decir esto de Orotava: que todo parece haber sido tenido en cuenta, su posición, clima, alrededores, residencias, sociedad, conveniencias, y por encima de todo, su proximidad con el pico. Es el punto más adecuado del archipiélago como residencia para extranjeros. No se haría justicia a Orotava si no se dijera que pronto será una segunda Funchal, con la que puede fácilmente rivalizar y ciertamente debe superar. Madeira como residencia de invierno para enfermos; además de tener atracciones que podrían inducir la salud allá y prevenir que alguna vez se convierta en el hospital melancólico que Funchal es.

${ }^{40}$ Elizabeth Murray, Sixteen Years of an Artist's life in Morocco, Spain and Canary Island, London, Hurst and Blackett Publishers, successors of Henry Colburn, 1859. In two Volumes. p. 171.
} 
aguas como una enorme planta piramidal de doscientos metros de altura. Todas las ramas están entrelazadas las unas con las otras, y el menor movimiento se transmite de hoja en hoja a través de la inmensa y verde campiña. Sin embargo, las colinas son muy escarpadas, y para ligarse unos a otros los árboles, grandes masas de ramas, bejucos y flores se esparcen de cima en cima, semejantes a los hilos de una catarata. Es un Niagara de verdura ${ }^{41}$.

Este enmarañamiento del que habla Reclus, le generó una sensación de agobio, una especie de confusión, pues no estaba acostumbrado a ver la complejidad del medio al que se aprestaba a entrar, por lo que este esplendor sobrepasaba cualquier idea de naturaleza concebida por el viajero. El control que el hombre europeo había efectuado sobre sus espacios y que le permitía un cierto aire de bienestar, se encontraba ahora ausente y la individualidad altiva del viajero europeo se manifestaba reducida, diminuta e incluso, impotente frente al trópico:

Es imposible no sentir una extraña conmoción física cuando uno deja tras de si la atmósfera ardiente y luminosa, para penetrar bajo la sombra húmeda y solemne de una selva virgen. A pocos pasos del mar, podía creerme internado a cien leguas del continente; por todas partes una confusión inextricable de ramas; por todas partes misteriosas profundidades en que la mirada se atreve apenas a fijarse; a mi alrededor, rocas cuyas paredes desaparecían bajo el follaje entrelazado; sobre mi cabeza, una bóveda de verdura a través de la cual penetraba una media luz que se veía en una y otra rama. Qué diferencia entre estos bosques tropicales y nuestras selvas calmadas y raquíticas, y nuestros bosques tajados, en que cada árbol herido por la hacha, se presenta débil como un enfermo y tuerce con angustia sus brazos delgados y sin gracia!

En los países amados del sol, a los árboles gigantescos que la tierra alimenta, les circula bajo la corteza una savia fuerte e impetuosa, y podría decirse que el suelo, el agua y la roca, se amalgaman allí para entrar más rápidamente en el círculo de la vida vegetal. Las cimas son más altas y cubiertas de vegetación, el color de las hojas y de las flores más variado, las aromas de estas son más acres; y no es el reposo, es el terror lo que se experimenta bajo estas tenebrosas sombras ${ }^{42}$.

Reclus, quien reconocía la complejidad de la naturaleza en el Caribe, manifestaba al mismo tiempo una incapacidad para comprenderla, y esta incapacidad se traducía, siguiendo sus propias palabras, en un miedo ante lo desconocido. Es cierto que intentará explicarla, traducirla haciendo uso del código cultural que le permite su lenguaje, para mostrarlo al público francés de donde procedía, pero, consciente o no de las limitaciones del lenguaje para transmitir los sentidos, se frustra y el gigante y complejo universo de plantas, flores, árboles y animales, todos unidos de manera que el geógrafo no sabía explicar, le causaba una sensación cercana al terror. Esta no fue, sin embargo, la percepción individual del que es considerado el padre de la geografía

\footnotetext{
${ }^{41}$ Eliseo Reclus, Voyage a la Sierra-Nevada de Sainte-Marthe. Paysages de la nature tropicale, Pari,: Librairie Hachette et C, 1869 , p. 32.

${ }^{42}$ E. Reclus, Voyage a la Sierra-Nevada, p. 33
} 
moderna. Por el contrario, su hermano, Armand Reclus, quien fuera oficial de la armada francesa, en su viaje de visita en Panamá, experimento igualmente lo mismo que Eliseo:

(...) nuestra embarcación atravesó pantanos cuya agua está cargada de tal manera de despojos vegetales, que en ciertos puntos es un fango líquido en donde las embarcaciones forman negros surcos, levantando emanaciones de un olor pestilencial; en seguida entramos en otros canales de riberas fangosas, donde solamente los cocodrilos y las tortugas pueden permanecer sin temor y en los que el hombre que se viese abandonado sin recursos, no viendo a su alrededor sino agua, fango y reptiles, se entregaría a la más completa desesperación. Esa naturaleza inhospitalaria me hacía estremecer, y deseaba con impaciencia respirar un aire menos cargado de miasmas funestos, ver un pedazo de tierra en la cual pudiera poner el pie con seguridad. Por fin entramos en un estrecho canal abierto por la mano del hombre a través de un terreno que se eleva algunas pulgadas de la línea de las inundaciones; al punto me pareció que el aire era más puro y me sentí curado de la fiebre que pérfidamente principiaba a inficionar mi sangre $^{43}$.

He aquí, pues, una evidente contradicción en el discurso: la definición de naturaleza se parece a lo conocido, lo observado, lo europeo. De aquí la enorme diferencia con las islas subtropicales antes mencionadas. El encuentro con espacios que no encajan con lo que ya tiene definición cultural, requiere de un esfuerzo mental por parte del visitante, que sobrepasa lo que el observador conoce, por tanto, ante lo inexplicable, se acude a la creación de narrativas que expliquen lo que no se comprende. De igual forma, el encuentro con seres que no encajan dentro del estereotipo conocido, generará mecanismos explicativos o al menos el intento de comprensión, en otras palabras, la definición o establecimiento de la otredad.

Volviendo con Canarias y la cuestión del clima. Como he afirmado, siguiendo las descripciones de viajeros que, al conocer los lugares del archipiélago que les permitieron llegar a la conclusión que este era el mejor clima del mundo, no tuvieron en cuenta a aquellos a los que no les parecieron tan agradables. Si bien es cierto que casi todos los viajeros hicieron alusión en sus recuerdos a los sitios donde el calor les fastidiaba la alegría, vale la pena preguntarse, ¿por qué predominó el discurso positivo sobre el clima de las islas? ¿Se debió, acaso, al hecho de repetirlo muchas veces en los círculos adecuados de la élite europea? Si las referencias a la sequedad de los suelos, la ausencia de suficientes fuentes hidrográficas, de vegetación y el calor en muchas partes de las islas no fueron suficientes para tumbar el argumento de la benignidad del clima, ¿cómo fue posible que en una región como el Caribe, donde, con excepción del excesivo calor, los demás factores se hallaban en una abundancia que sorprendía, se identificara esta como lo más cercano a un infierno?

${ }^{43}$ Armand Reclus, Exploraciones a los istmos de Panamá y Darién en 1876, 1877 y 1878, Madrid, Imprenta de Enrique Rubinos, 1881, p. 71. 
Alexander Von Humboldt llamó al clima de Santa Cruz, en sus cortos días de visita en las islas, de camino hacia el Nuevo Mundo, como very oppresive, es decir, muy agobiante, y esta fue la misma sensación que expresó al visitar La Guayra, en la costa venezolana y también en Cartagena a finales del siglo XVIII, pero ninguna otra afirmación expresada por el famoso científico naturalista y viajero alemán puede definir mejor mi argumento: "The perpetual coolness which prevails at La Laguna causes it to be regarded in the Canaries as a delightful abode"44, lo cual permite conectar con lo experimentado por Florence Du Cane un siglo más tarde: "Arid slopes rise gradually behind the town, and appear to be utterly devoid of vegetation. Perched on a steep ridge is the Hotel Quisisana, which cannot be said to add to the beauty of the scene, and all my sympathy went out to those who were condemned to spend a winter in such desolate surroundings in search of health" 45 .

La gran mayoría de los viajeros que visitaron el archipiélago estaban de acuerdo en que, con excepción de algunos sitios específicos, lógicamente en las zonas altas de montaña, la gran mayoría del territorio que ocupan las islas era seco y de clima tropical, sin embargo la imagen construida sobre las mismas no fue adversa en términos de los discursos eurocentristas, porque, como he afirmado antes, el asunto es que esos espacios encajaban mejor dentro de las necesidades climáticas de aquellos que sufrían las calamidades de vivir en climas fríos.

\section{La búsqueda de la salud en el trópico andino}

Ahora bien, esta búsqueda de lugares donde mejorar la salud respiratoria de los invalids, no sólo se llevó a cabo en Europa. Casos como el de Perú y Colombia se pueden notar en el interés que algunos científicos trataron de generar dadas las bondades de los climas en sus respectivos lugares de procedencia.

En 1806 se publicó en Lima el libro Observaciones sobre el clima de Lima, del médico ariqueño Hipolito Unanué ${ }^{46}$. El libro, que está dividido en tres partes, bien podría parecer una respuesta -desde el sur-, a los planteamientos que, sobre la negatividad de los climas tropicales, se venían construyendo desde el universo ilustrado europeo. Sin embargo, Unanué no cuestiona las

\footnotetext{
${ }^{44}$ Alexander Von Humboldt citado por Florence Du Cane, The Canary Islands, London, Adan and Charles Black, 1911, p. 11. El perpetúo frescor que prevalece en La Laguna hace que sea considerada en las Canarias como una agradable morada. 45 F. Du Cane, The Canary Islands, p. 11. Áridas laderas ascienden gradualmente detrás del poblado y aparecen completamente desprovistas de vegetación. Trepado en una empinada cresta está el Hotel Quisisana, del que no se puede decir que añada belleza al paisaje, y toda mi simpatía se fue para aquellos que en busca de salud estaban condenados a pasar un invierno en un paraje tan desolado.

${ }^{46}$ Hipólito Unanue, Observaciones sobre el clima de Lima y sus influencias en los seres organizados, en especial el hombre, Lima, Imprenta Real de los Huérfanos, 1806. Algunos trabajos que han abordado el libro de Unanue como tema de estudio son: Victor Garcia-Belavente, El clima de Lima y sus influencias según Hipolito Unanué, http://www.academia.edu/1495904/El clima de Lima y sus influencias seg\%C3\%Ban Hip \%C3\%B3lito Unanue. 2005, Juan-Pablo Murillo, "Hipolito Unanue y el proceso de construcción del discurso epidemiológico peruano". Anales de la Facultad de Medicina, 66, (4), 2005: 344-356; Oswaldo Salaverry, 'Las observaciones sobre el clima de Lima' (1806) de Hipolito Unanué como topografia ilustrada, Tesis doctoral Universidad de Salamanca. Departamento de Ciencias Biomédicas y del Diagnóstico, 2016.
} 
posturas del momento sobre los efectos contraproducentes del calor en el ser humano, es decir, del trópico, sino que más bien, los matiza a través de una argumentación muy inteligente que se puede apreciar desde el momento inicial de su narrativa:

La vida del hombre parece que subsiste por los estímulos internos..., y por los externos de las impresiones de los cuerpos que lo rodean...

La luz del Sol ocupa el primer lugar en el número de los estímulos exteriores. No hay vida en donde no penetran los rayos de este astro benéfico; y en las regiones que esclarecen, solo arde a medias en su ausencia, la lámpara vital quasi apagada por el sueño imagen de la muerte... Este estimulo, espíritu de la naturaleza corpórea, debe con todo guardar cierto temple en las impresiones que nos hace. Nuestra delicada estructura no puede soportarlas en toda su fuerza; porque el calor excesivo que resultaría de ellas, consumiendo los líquidos, y desbaratando el enlace y trabazón de los sólidos, reduciría a ceniza lo mismo que anima en un grado moderado. Temiendo los antiguos aconteciese esto en la Zona Tórrida, donde el Sol despliega toda su intención, lo juzgaron inhabitable ${ }^{47}$.

Dicho de otra manera, Unanué, que, dicho sea de paso, se apoyaba en los antiguos $^{48}$, entendía que el efecto desmedido, -entiéndase, sin temple-, de los rayos del sol, provocaría que las uniones de los átomos, se desdoblaran; los líquidos (nuestra sangre), se esfumara y los sólidos, es decir, nuestros miembros, se partieran y nos volviéramos chicharrones. Por tanto, se hacía necesario un punto medio en el que los rayos del sol tuvieran un efecto con temple, es decir, un espacio con condiciones propicias para la vida, no como la zona tórrida, donde vivían los habitantes del Caribe colombiano, sino aquella zona de las bondades para la vida que también defendía Francisco José de Caldas, el ilustrado novogranadino, haciendo acopio de argumentos de una claridad argumentativa que solo es comparable con los argumentos de Unanué.

Prosigo con Unanue, quien además sostenía que, con el cambio de estación climática, los temperamentos cambiaban, se volvían más extasiados:

El punto más notable en el equinoccio de Septiembre en que comienza la primavera*. Todo anuncia que vuelve el norte el astro del día a calentar nuestras regiones. El fuego diseminado en la naturaleza se pone en movimiento, y todos los seres aumentan su volumen y transpiración. La atmósfera toma mayor elevación, y enrarecida del lado del equador soplan con fuerza los vientos australes. Los vapores se levantan a más altura de la superficie de la tierra, y en sus entrañas con más frecuentes las combustiones. El calor reduce a vapor una parte de sus aguas subterráneas, las pone en expansión, excita la chispa eléctrica, y las inflama. Por eso hacia Octubre repiten más a menudo nuestros terremotos, y las erupciones de los volcanes: y los relámpagos que observamos por la banda del norte

\footnotetext{
${ }^{47}$ H. Unanue, Observaciones sobre el clima de Lima, p. 2.

${ }^{48}$ Unanué se acoge a los antiguos, pero no queda claro si se refería a los griegos y romanos o si, por el contrario, se estaba refiriendo a discusiones del renacimiento sobre los efectos negativos de los rayos del sol.

* Cabe aclarar que el comienzo de la primavera en América del Sur es diferente de aquel que se experimenta en Canarias y en Europa, el cual empieza a mediados del mes de abril y principios de mayo. Nota en el original.
} 
indican la electricidad de la atmósfera. Aunque nuestra vegetación sea perpetua, adquiere en esta estación nueva gracia, vistiéndose los jardines de las flores más hermosas que tenemos ${ }^{49}$.

Y no sólo eso, este cambio, también alteraba la inteligencia y los temperamentos de los sexos -y, siguiendo la lógica de género del momento-, mucho más el de las mujeres:

Los animales sienten un estímulo más activo que los induce a la conservación de su especie, y hasta la imaginación humana adquiere no sé qué grado de vehemencia, y energía. He observado que la juventud Peruana es mas eloqüente, y fecunda en primavera que en hibierno, y las obras de nuestros artistas, aunque atrasados, suelen adquirir tal ayre de animación, que parece que Prometeo ha robado la luz del Sol para animar las sombras y el barro, por medio del pincel, y el buril.

Este calor que adquiere en este tiempo nuestra sensible imaginación origina las manías, éxtasis, y otras alucinaciones comunes a los dos sexos, aunque más el femenil. Las disipa el frio artificial, o el natural hibierno, no sin dolor del poseído, pues juzga con el Poeta que es una muerte el desengaño ${ }^{50}$.

Los planteamientos de Unanué, basados inalterablemente en lo que el título de su libro sugiere, observaciones, no dejan de ser, al fin y al cabo, el resultado del primer paso del método científico que los intelectuales del siglo XIX impulsaban como herramienta que habría de llevar a la humanidad a un anunciado progreso, el progreso del proyecto filosófico de la modernidad. La comprobación, de estas observaciones, resultan, para los efectos de este estudio, de poco o ningún interés. Lo que si resulta interesante, es la construcción de un discurso que indudablemente se alineaba con las posturas que veían en el trópico, y en los efectos del sol sobre los seres vivos, una alteración de las conductas que, según Unanué, tenían un efecto temporal en la vida de los jóvenes peruanos, -mientras la primavera durara-, pero que, para el caso de aquellos que vivían en las zonas tropicales, y de acuerdo con dichas observaciones, debía ser constante, por lo que mientras vivieran en ellas, la conducta moral debía permanecer invariable, y esto quiere decir, sin una evolución positiva hacia lo civilizado.

De esta manera, lo que Unanué llamaba manías, resultado del éxtasis generado por la presencia del calor, era la alegría que Glas igualmente observaba en las mujeres Canarias, mismas que el viajero relacionaba con África y no con Europa y a las que quiso dedicarle un libro que no llegó a concretarse, debido a su súbita e inesperada muerte de camino a Inglaterra. Esta relación entre calor y conducta moral, la define muy bien David Spurr cuando afirma que:

(...) to establish a connection between the moral standing of a people and its climatic environment. The heat of the tropics, according to this logic,

\footnotetext{
${ }^{49} \mathrm{H}$. Unanue, Observaciones sobre el clima de Lima, p. xviii.

${ }^{50} \mathrm{H}$. Unanue, Observaciones sobre el clima de Lima, p. xix.
} 
produces races characterized by indolence and easy sexuality, while the harsher conditions of northern climates have created a race devoted to diligence and self-control ${ }^{51}$.

Ahora bien, ¿por qué hablar de clima y sexualidad? Tal vez porque Unanué (1755-1833), quien fue contemporáneo con Caldas (1768-1816), -para el caso de la Nueva Granada-, es decir, ambos vivieron durante la segunda mitad del siglo XVIII y principios del XIX, buscó distanciarse de las hipótesis asumidas como ciertas-, que veían el sur como trópicos expuestos a las inclemencias y en los que las posturas científicas en boga establecían una separación con criterios de valor social entre trabajo e indolencia o entre disciplina e indulgencia ${ }^{52}$.

Tal vez por ello, -y al igual que Caldas, a quien seguramente conocía, o habrían sabido el uno del otro, pues los dos se mantuvieron en contacto con Humboldt-, ambos escribieron tratados sobre la influencia del clima en el comportamiento de los seres vivos. No fue tampoco una coincidencia que ambos encontraran en las zonas de montaña, un parecido con el clima benévolo y más acorde con el discurso de distanciamiento de las narrativas coloniales europeas, muy en sintonía con el discurso científico del siglo XIX:

Resulta (...), que Lima situada en el centro de la parte austral de la zona tórrida, refrescada continuamente por los sures, vientos húmedos $\mathrm{y}$ nebulosos, y rodeada por el oriente y norte de cadenas de cerros, goza de un temperamento cálido y húmedo; en que ambas qüalidades se atemperan de manera entre sí, que parece una continuada primavera al compararse con el de los climas transtropicales. Su atmósfera, lluvias, y truenos, mantiene suspensa una gran cantidad de vapores que en continua lucha con la luz solar, forma unos días varios del uno al otro extremo del año. Estas mutaciones diurnas no alteran el termómetro si se corresponden entre cortos espacios. Debe prevalecer la iluminación solar, o la espesura de las nubes por algún tiempo, para que se hagan sensibles su ascencion o descenso ${ }^{53}$.

Calor y humedad, eran las dos variables que usó Unanue para construir una topografía acorde con un discurso de clima beneficioso para la salud. Por ello se dedicará en la tercera parte de su libro a identificar los aspectos del clima que influyen en la mejoría de las enfermedades y, por supuesto, para ello el clima de Lima como mutación perfecta, será un buen espacio. Caldas, por su parte, identificara en la región media de los Andes, el clima ideal, coincidiendo con las posturas de Unanué: La región media de los Andes...con un clima dulce y moderado...produce árboles de alguna elevación, legumbres, hortalizas saludables, mieses; todos los dones de Ceres: hombres

\footnotetext{
${ }^{51}$ David Spurr, The Rhetoric of Empire. Colonial Discourse in Journalism, Travel Writing and Imperial Administration. Durham: Duke University Press, 2001, p. 41. Establece la conexión entre la posición moral de la gente y su ambiente climático. De acuerdo con esta lógica, el calor de los trópicos, produce razas caracterizadas por la indolencia y una sexualidad más abierta, mientras las condiciones más duras de los climas del norte han creado una raza dedicada a la diligencia y al auto control.

52 D. Spurr, The Rhetoric of Empire, p. 41.

${ }^{53} \mathrm{H}$. Unanue, Observaciones sobre el clima de Lima, p. liii.
} 
robustos, mujeres hermosas, bellos colores son el patrimonio de ese suelo feliz ${ }^{54}$.

Ahora bien, en 1878, el médico norteamericano Erastus Wilson, publicó lo que se puede llamar un pequeño compendio de ideas, en las que, manteniendo el mismo modelo de pensamiento en torno a los espacios tropicales, y al impacto negativo sobre los seres vivos, veía, sin embargo, en los cerros de la altiplanicie ocupada por la capital de la Nueva Granada, un clima propicio para la creación de residencias sanitarias durante el invierno ${ }^{55}$. El compendio, que es en realidad su memoria de viaje, resultado de un recorrido llevado a cabo por el galeno a finales del año 1877, cuenta con una extensión de 150 cuartillas en las que Wilson describe sus peripecias en el Etna, de camino entre New York y el Caribe antillano, y luego desde las costas del Caribe colombiano, hasta llegar a Bogotá.

Wilson, quien coincide con las apreciaciones de Unanué, no parece haber estado en contacto con su obra. No hay mención alguna de los trabajos del médico peruano en lo relativo a la influencia del clima en los seres humanos, sin embargo, en un aparte de su escrito sostiene lo siguiente:

Moisture and heat, the two chief instruments of vegetation; the one the vehicle, the other the motor power, both here so abundant, have spread over it a most luxuriant growth of forest trees and undergrowth, and matted them together with creeping and climbing plants, into one impenetrable mass of jungle; a chosen home of the Crocodilia, which find it its solitude and lagoons the conditions favorable to their propagation ${ }^{56}$.

Calor y humedad, pero sin la mutación milagrosa, como lo pensó Unanue, para dar con el ambiente perfecto donde los cocodrilos encuentran su hogar.

Sin embargo, este no era un espacio propicio para el desarrollo pleno de la vida, en palabras de Caldas (1966); aunque contradictoriamente, si lo era para generar un caos de exuberancia más allá de cualquier idea de vida imaginable en el pensamiento ilustrado latinoamericano del siglo XIX.

De este pensamiento acorde con los postulados de Unanue, aunque al parecer sin conocerlos, Wilson encontrará sosiego intelectual, pero, sobre todo, descanso corporal, en el ambiente de la meseta donde reposa Bogotá:

The climate is bracing, though the absence of our accustomed amount of atmospheric pressure is sensible felt, the cheering, gurgling ripple of the mountains rivulets, as their cool, sparkling waters, clear as crystal, rush by us, produce in us very pleasing sensations. We have for the nonce,

\footnotetext{
${ }^{54}$ F. José de Caldas, El influxo del clima. (Las cursivas en el original)

${ }^{55}$ Erastus Wilson, A ramble in New Granada, New York, G.W. Carleton \& Co., Publishers, 1878.

${ }^{56}$ E. Wilson, A ramble in New Granada, p. 38. Humedad y calor, los dos instrumentos principales de la vegetación; uno es el vehículo y el otro la potencia motora, los dos aquí tan abundantes, han extendido el más exuberante desarrollo de árboles de la selva y maleza y lo han mezclado juntos con plantas trepadoras, en una masa impenetrable de jungla; el hogar escogido por el cocodrilo, el cual ha encontrado en estas soledades y lagunas, las condiciones favorables para su propagación.
} 
forgotten all our cares in the absorbing sensations produced by our surroundings and are in the best of humors ${ }^{57}$.

De esta manera, aunque Wilson adolece al momento de su llegada a Bogotá de bronquitis, misma que acusa haber cogido al pernoctar al aire libre en el vapor de camino entre Barranquilla y Honda, las buenas energías que percibe en la capital, le permiten empezar a sentirse mejor:

The thermometer ranges between 60 and 65 of Fahrenheit's scale, and we are assured ny the physicians that it does not vary much beyond these limits during the entire year, if we except the months of June, July and August, when the cold winds blow from the mountains. The physicians and people boast that consumption (Phthisis Pulmonalis) is unknown here. We soon discover that although the diurnal changes of temperature are very slight, yet there are marked changes in the humidity of the atmosphere, and that our bronchitis sympathizes considerably with these changes ${ }^{58}$.

No obstante, de aquellos espacios que durante las primeras impresiones parecían indicar que la ciudad y sus alrededores podrían albergar a aquellos desvalidos que buscaban espacios con condiciones para mejorar su calidad de vida, algo faltaba en la Bogotá de entonces que no permitió una conclusión positiva de la visita de Wilson para convertirla en un espacio propicio para la recuperación de los invalids, pues luego de algunos días observando las condiciones sanitarias, el galeno llegó al siguiente veredicto:

Thus this city, surrounded by physical conditions favorable for making it one of the healthiest on the planet; situated over a clay sub-strata of easy excavation for the construction of sewers, and connecting the closets with them by impermeable walls of masonry; with abundance of water from the mountain streams to flow through them in an average declivity, of fifteen degrees thus giving a rapid current capable of carrying the sewage down into the plain far away from the city, where it would become a source of revenue as an appropriate fertilizer of that cold soil, it does not, nevertheless, in its present state, offer the conditions of salubrity suited to the requirements of health seekers ${ }^{59}$.

\footnotetext{
${ }^{57}$ E. Wilson, A ramble in New Granada, p. 58. El clima es reconfortante, aunque la ausencia de nuestra acostumbrada presión atmosférica es sensiblemente notable, el borboteo de los riachuelos de las montañas, como sus frescas aguas espumosas, claras como el cristal, pasan rápidamente a nuestro lado, nos produce unas sensaciones muy placenteras. Hemos olvidado, por el momento, todas nuestras preocupaciones en las absorbentes sensaciones producidas por el ambiente que nos rodea y el mejor de los humores.

${ }^{58}$ E. Wilson, A ramble in New Granada, p. 63. ${ }^{\mathrm{E}} 1$ termómetro oscila entre 60 y 65 de la escala Fahrenheit y hemos sido asegurados por los médicos que no varía mucho más allá de estos límites durante todo el año, con excepción de los meses de Junio, Julio y Agosto, cuando los vientos fríos soplan desde las montañas. Los médicos y la gente alardean que la tisis (Phthisis Pulmonialis) es desconocida aquí. Rápidamente nos hemos dado cuenta que aunque los cambios diurnos de temperatura son muy leves, sin embargo estos son marcados cambios en la humedad de la atmósfera, y que nuestra bronquitis simpatiza considerablemente con estos cambios.

${ }^{59}$ E. Wilson, A ramble in New Granada, p. 73. Así esta ciudad, rodeada de favorables condiciones físicas para hacerla una de las más saludables del planeta, situada sobre substratos de arcilla de fácil excavación para la construcción de alcantarillados, y conectándolos con paredes de mampostería; con abundancia de agua provenientes de las corrientes montañosas que fluyen directamente a través de estos en un declive promedio de quince grados, dando así un torrente rápido capaz de llevar las aguas residuales hacia los llanos, lejos de la ciudad, donde podrían convertirse en una fuente de ingresos como fertilizante apropiado de ese suelo frio, sin embargo, en su estado actual, no ofrece las condiciones de salubridad adecuadas para los requerimientos de los que buscan mejorar su salud.
} 
El discurso sobre los trópicos tenía unas flaquezas que se apoyaban en la idea generalizada -y sostenida desde los círculos académicos-, de que la vida en estas regiones no podía desarrollarse adecuadamente. La vida en el trópico que observaban los viajeros, pero en especial, aquellos que se dedicaban a investigarla, bien sea por curiosidad o por profesión, hablo aquí de científicos y naturalistas; era una vida desordenada, compleja e imperfecta. Los seres que lograban adaptarse a ella, necesitaban de la presencia iluminadora de la mano europea para salir del estado salvaje en el que se encontraban.

Curiosamente, para el caso de Canarias, prácticamente ningún científico local tuvo que darse a la tarea de defender el clima de las islas, el mismo discurso colonial europeo, difundido por viajeros a través de sus relatos de viaje, lo hizo para su conveniencia (la de los invalids además de todas aquellas personas que tenían cómo sufragar un viaje para escapar de la estación fría). Habrá que preguntarse si la división de los climas terrenales en frio, templado y cálido, tiene alguna ascendencia en lo que Unanué expresó en su libro.

\section{Conclusión}

Más allá de las concepciones sobre el trópico y sus fuerzas naturales, sus animales salvajes y los seres humanos que lo habitaban, creadas con base en los relatos de naturalistas, científicos y aficionados a los viajes por tierras exóticas, el espacio contenía unas geografías de la salud construidas asimismo desde el interior de los discursos científicos europeos que volvieron esa zona del mundo en una distopía, aquello que era todo lo contrario a los poemas de ensoñación del renacimiento, donde la verde campiña hacía de los paseos una delicia para el crecimiento espiritual. Sin embargo, en esa distopía, no todo era malo. Existían regiones donde era posible que ciertas condiciones se dieran para que aquellos atados a una cama, dadas sus afecciones respiratorias, pudieran dar un paseo al aire libre y disfrutar de un ambiente más cálido y acogedor mientras se recuperaban. Así lo veía Belcastel:

Sé únicamente lo que sabe la muchedumbre, lo que desde Hipócrates se dice en todos los libros sobre esta materia, lo que todos los dias la facultad repite á millares de enfermos:- que la mejor de las condiciones en que se podria colocar á la naturaleza para restablecerla por sus propios medios, seria una larga residencia en un clima dulce, igual y sin nieblas ni escarchas, donde la savia nunca muere, donde sean raras las lluvias, donde los vientos y las borrascas sean conocidos apenas; y yo habria dicho desde luego, donde reine una eterna primavera, si por una parte las tan erróneas aplicaciones de esta palabra, no hubieran hecho de ella una reconocida falsedad, y si de otra parte, la primavera no hubiera desde algunos años acá perdido con justicia su vieja reputación. (Que Dios preserve á los enfermos de la primavera de Francia!) Mas lo que voy á decir, ya que el mismo mundo médico no lo sabe suficientemente, es el punto del globo donde están esos benditos cielos y la facilidad ofrecida á la mayor parte de las familias para buscarlos y vivir en ellos (...). No, no, no es en Italia donde se ha de buscar, no es en Europa, diversa en su clima como en el genio de 
sus pueblos, tampoco en la estension del lago Mediterráneo, campo de batalla de los vientos del norte y de los del mediodía, que poco á poco hacen pasar sobre él el aire abrazador del África ó el aire desgarrador de las zonas nevadas. Es bajo sombras á la vez mas tibias y menos ardientes. Allá donde el plátano estiende sus hojas sin que el invierno las hiera, allá donde la palmera muestra sus frutos sin que los pueda madurar el estío. Ese clima, los ingleses, mas esploradores que nosotros, mas amenazados también por el estrago del mal, lo han presentido, lo han casi hallado ${ }^{60}$.

De otro lado, esa búsqueda del sol, pero no aquel ardiente de las selvas africanas o de las zonas desérticas del Sahara, sino uno que generara un clima medio, más hospitalario, no fue solo la búsqueda de los europeos. En ello también se empeñaron las elites al otro lado del Atlántico, como lo hicieron los médicos Erastus Wilson, e Hipólito Unanue, para el caso de los Andes o algunos otros galenos en las islas del Caribe antillano, con la intención de localizar esas geografias de la salud tan necesarias.

Lo que hoy conocemos como turismo masivo, debe sus inicios a esa búsqueda que posteriormente daría paso a otros intereses menos vitales, pero igualmente necesarios para el anhelo humano de conocer el mundo en el que habita.

\section{Bibliografía:}

\section{Fuentes Primarias:}

Belcastel, Gabriel de, Les Iles Canaries et la vallee d'Orotava au point de vue hygienique et medical, Paris, J.B. Bailliere et Fils, 1861.

Belcastel, Gabriel de, Las Islas Canarias y el Valle de la Orotava bajo el punto de vista médico e higiénico. Santa Cruz de Tenerife, Imprenta y Litografia Isleña, 1862.

Burton, Richard F., Mis viajes a las Canarias. Edición y estudio introductorio de Nicolás González Lemus. La Laguna, Tenerife, Nivaria Ediciones, 2004.

Caldas, Francisco José de, "El influxo del clima sobre los seres organizados, por Don Francisco Joseph de Caldas, individuo meritorio de la Expedición Botánica de Santafé de Bogotá, y encargado del Observatorio Astronómico de esta capital", en Semanario del Nuevo Reyno de Granada, 22, Santafé de Bogotá, 29 de mayo de 1808.

Caldas, Francisco José de, Obras Completas, Bogotá: Universidad Nacional de Colombia, 1966.

Clark, James, The influence of climate in the prevention and cure of chronic diseases, London, Thomas and George Underwood Publishers, 1829.

Clark, James, The sanative influence of climate: with an account of best places of resort for invalids, Philadelphia, A. Waldie Publisher, 1841.

\footnotetext{
${ }^{60}$ G. de Belcastel, Les Iles Canaries et la valle, p. 11.
} 
Cooper, William W., The invalid's guide to Madeira with a description of Teneriffe, Lisboan, Cintra, Mafra, etc., London, Smith, Elder \& Co. Publishers, 1840.

Du Cane, Florence, The Canary Islands, London, Adan and Charles Black, 1911.

Glas, George, The history of the discovery and conquest of the Canary Islands, Dublin, Printed for D. Chamberlaine, 1764.

Latimer, Isaac, Notas de un viaje a las islas de Tenerife y Gran Canaria. Un clima de verano en invierno, La Orotava, J.A.D.L editores, 2002.

Murray, Elizabeth, Sixteen Years of an Artist's life in Morocco, Spain and Canary Island. London, Hurst and Blackett Publishers, successors of Henry Colburn, 1859. In two Volumes.

Nelson, Wolfred, Five years at Panama. The trans-isthmian canal, New York, Belford Company Publishers, 1889.

Piazzy Smith, C., Madeira meteorologic, Edinburgh, David Douglas Publisher, 1882.

Reclus, Armand, Exploraciones a los istmos de Panamá y Darién en 1876, 1877 y 1878, Madrid, Imprenta de Enrique Rubinos, 1881.

Reclus, Eliseo, Voyage a la Sierra-Nevada de Sainte-Marthe. Paysages de la nature tropicale, Paris, Librairie Hachette et C, 1869.

Samler Brown, A., Madeira and the Canary Islands. A practical and complete uide for the use of invalids and tourists, London, Sampson Low QMarston \& Co, 1894.

Stone, Olivia, Tenerife and its six satellites or the Canary islands past and present, London, Marcus Ward \& Co. Limited, 1889.

Unanue, Hipolito, Observaciones sobre el clima de Lima y sus influencias en los seres organizados, en especial el hombre, Lima: Lima, Imprenta Real de los Huérfanos, 1806.

Wilde, William R., Narrative of a Voyage to Madeira, Tenerife and along the shores of the Mediterranean, Dublin, William Curry, Jun and Company, 1840. Two Volumes.

Wilde, William R., Narración de un viaje a Tenerife, Santa Cruz de Tenerife, Ediciones Idea, 2004.

Wilson, Erastus, A ramble in New Granada, New York, G.W. Carleton \& Co., Publishers, 1878.

Whitford, John, The Canary Islands as a winter resort, London, Nabu press, 1890.

\section{Fuentes Secundarias:}

Aries, Phillipe, Duby, George, El proceso de cambio en la sociedad de los siglos XVIXVIII. En:Historia de la Vida Privada, Tomo 5. Madrid: Taurus, 1992. 
Bolufer, Mónica, Mujeres e Ilustración. La construcción de la feminidad en la España del siglo XVIII, València: Instituciò Alfons el Magnànim, 1998.

Corbin, Alain, Courtine, Jean Jacques y Vigarello, Georges, Historia del Cuerpo. Madrid: Taurus, 2005, Vol. 1.

Garcia-Belavente, Victor, El clima de Lima y sus influencias según Hipolito Unanué. En:(http://www.academia.edu/1495904/El clima de Lima y sus influencias seg\% C3\%Ban Hip\%C3\%B3lito Unanue. 2005

Gonzalez Lemus, Nicolas, Clima y medicina. Los origenes del turismo en Canarias. Santa Cruz de Tenerife: Ediciones Idea, 2007.

Iriarte, Cristina de y Curell, Clara, Introducción a La Orotava y la magia de su clima de Gabriel de Belcastel. Santa Cruz de Tenerife: Ediciones Idea, 2004.

Kidd, Benjamin, The control of the tropics. New York: The Macmillan Company, 1898.

Kidd, Benjamin, Social Evolution. London: Macmillan and Co., Limited, 1906.

Lain Entralgo, Pedro, Historia de la Medicina. Barcelona: Salvat Editores, 1978.

Murillo, Juan-Pablo, Hipolito Unanue y el proceso de construcción del discurso epidemiológico peruano. En: Anales de la Facultad de Medicina. 66, (4), 2005.

Neill, Deborah J., Networks in Tropical Medicine: Internationalism, Colonialism, and the Rise of a Medical Specialty, 1890-1930. Stanford University Press, 2012.

Salaverry, Oswaldo, 'Las observaciones sobre el clima de Lima' (1806) de Hipolito Unanué como topografía ilustrada. Tesis doctoral. Universidad de Salamanca. Departamento de Ciencias Biomédicas y del Diagnóstico, 2016.

Singer, Charles y Underwood, E. Ashworth, A short history of Medicine. Oxford: Clarendon Press, 1962.

Spurr, David, The Rhetoric of Empire. Colonial Discourse in Journalism, Travel Writing and Imperial Administration. Durham: Duke University Press, 2001. Fifth edition.

Wade, Nicholas, Una herencia incomoda. Genes, raza e historia humana. Barcelona: Ariel, 2015.

Wade, Peter, Degrees of Mixture, Degrees of Freedom: Genomics, Multiculturalism, and Race in Latin America. Duke University Press, 2017. 